\title{
(Re) pensar o ato de planejar via necessidades formativas de professores de Matemática
}

\author{
Kely Fabrícia Pereira Nogueira \\ Patrícia Sandalo Pereira
}

\section{Resumo}

Este artigo traz um singular recorte da pesquisa que vem sendo desenvolvida no Programa de Pós-Graduação em Educação Matemática, em nível de Doutorado, na Universidade Federal de Mato Grosso do Sul (UFMS). Ele tem como objetivo explanar sobre a dinamicidade, a complexidade e a mutabilidade das necessidades formativas dos professores de Matemática em formação, a partir da parceria colaborativa no (re) pensar o ato de planejar. O referencial teórico deriva de três campos intrinsecamente ligados: formação de professores, análise de necessidades e práxis. A metodologia foi baseada na pesquisa colaborativa, com subsídios nas narrativas diárias e nos diálogos dos professores de Matemática em formação. A análise dos dados revelou possibilidades reais e abstratas, visto que as necessidades formativas centralizaram-se nas interações humanas.

Palavras-chave: Educação Matemática; Necessidades Formativas; Formação inicial de professores; Colaboração.

\section{(Re) think the act of planning through the forma- tion needs of Mathematics teacher}

\section{Abstract}

This article brings a singular cut of the research that has been developed in the Postgraduate Program in Mathematics Education, Doctorate level, in Universidade Federal de Mato Grosso do Sul (UFMS). His objective is explain the dynamism, complexity and mutability of the formation needs of the Mathematics teachers, through the collaborative partnership in (re) thinking the act of planning. The theoretical framework derives from three intrinsically linked fields: teacher formation, needs analysis and praxis. The methodology was based on the collaborative research, with 
subsidies in daily narratives and dialogues of Mathematics teachers in formation. The analysis of the data revealed real and abstract possibilities, since the formative needs are centered in the human interactions.

Keywords: Mathematics Education; Formative Needs; Initial Formation of Teachers; Collaboration.

\section{(Re) pensar el acto de planear por medio de las necesidades formativas de profesores de Mate- mática}

\section{Resumen}

Este artículo trae un singular recorte de la investigación que viene siendo desarrollada en el Programa de Postgrado en Educación Matemática, a nivel de Doctorado, en la Universidad Federal de Mato Grosso do Sul (UFMS). El objetivo es explicar la dinámica, la complejidad y la mutabilidad de las necesidades formativas de los profesores de Matemática en formación, a partir de la investigación colaborativa en el (re) pensar el acto de planear. El referencial teórico deriva de tres campos intrínsecamente ligados: formación de profesores, análisis de necesidades y praxis. La metodología fue basada en la investigación colaborativa, con subsidios en las narrativas diarias y en los diálogos de los profesores de Matemáticas en formación. El análisis de los datos reveló posibilidades reales y abstractas, ya que las necesidades formativas se centralizaron en las interacciones humanas.

Palabras-clave: Educación Matemática; Necesidades Formativas; Formación inicial de profesores; Colaboración.

\section{Introdução}

Discutir necessidades e análise de necessidades formativas dos homens vivos possibilita-nos discutir as necessidades dos professores, que fazem parte desses homens vivos, professores com uma especificidade, a "Matemática", visto que, corroboramos que não há homens vivos e vida profícua e independente se os sujeitos não forem atendidos nas suas necessidades.

Partindo desse entendimento, reconhecemos que "Professor" é uma palavra antiga, que se recorrêssemos a história, veríamos que nem sempre existiu esse nome para quem ensina, media, possibilita 
o aprendizado, instrui, encaminha, direciona, transmite o conhecimento. Perceberíamos uma variedade de palavras, tais como: "pais", "mestres", "pedagogos", dentre outros. (MANACORDA, 2010)

Logo, Professor de Matemática é muito mais recente e é estritamente sobre esse sujeito que queremos dialogar, pois fazemos parte dessa adjetivação - professores de Matemática. Ponte, Januário, Ferreira e Cruz (2000, p. 7-8) descrevem algumas funções desse sujeito

[..] funções do professor, como aquele que ensina qualquer coisa a alguém. É nesta relação triádica que encontramos a essência da actividade do professor. No entanto, esta actividade é marcada por muitos outros aspectos, que importa igualmente ter em consideração. $\mathrm{Na}$ verdade, o professor é um profissional, que exerce uma função remunerada no sistema de ensino público ou privado. O professor é um cidadão, o que lhe confere uma dimensão cívica e política incontornável. O professor é uma pessoa com sentimentos, valores, preocupações e emoções, pelo que a sua dimensão humana, moral e afectiva não pode ser negligenciada. O professor é ainda um membro da organização escolar e da comunidade educativa, pelo que tem igualmente uma dimensão organizacional e associativa, integrando uma cultura profissional específica.

Partindo desse diálogo, objetivamos explanar sobre a dinamicidade, a complexidade e a mutabilidade das necessidades formativas dos professores de Matemática em formação, a partir da parceria colaborativa no (re) pensar o ato de planejar, baseados na singularidade das aulas de Prática de Ensino de Matemática III. Nessa perspectiva, o presente artigo é um singular recorte da pesquisa que vem sendo desenvolvida no Programa de Pós-Graduação em Educação Matemática, em nível de Doutorado, na Universidade Federal de Mato Grosso do Sul (UFMS).

Para tanto, organizamos o artigo de forma que, primeiramente, discutimos as necessidades formativas, o que é planejar e, em seguida, assinalamos alguns pontos sobre a conexão entre os professores de Matemática em formação via necessidades formativas, em particular, sobre o ato de planejar, vislumbrando o planejamento. Logo após, apresentamos o caminho percorrido na 
realidade concreta para a materialização desses diálogos. Em sequência, evidenciamos a análise de dados, onde a essência mostra-se em sua totalidade, constituída a partir das particularidades do todo. Por fim, trazemos as considerações sobre as materializações evidenciadas e discutidas, reforçando o não acabamento de nada, pois fazemos parte de um sistema aberto e em constante movimento e somos seres, como afirma Freire (1999), inconclusos, inseridos no permanente movimento de procura e de novas necessidades.

\section{Necessidades Formativas}

Como seres sociais e relacionais, vivemos em uma época dinâmica, de revoluções sociais, em que todos os aspectos do conhecimento do mundo, na sua diversidade, ora se aprofundam e alargam, movimentos bruscos de libertação, “[...] século do progresso impetuoso da ciência e da técnica. As profundas transformações da vida social, a luta dos sistemas mundiais, a luta político-ideológica [...]" (KONSTANTINOV, 1975, p. 19). Isso o autor já afirmava há muito tempo atrás e hoje, ainda podemos verificar tal constatação.

Essa constatação remete ao início, que, segundo Marx e Engels (2007), os homens necessitam de condições para viver, essa condição permite-lhes fazer história e movimentarem-se na perspectiva da transformação.

No entanto, para viver é preciso, antes de qualquer coisa, comer, beber, ter moradia, vestimentas, dentre outras coisas. Marx e Engels (2007, p. 33, grifo nosso) evidencia que a "produção dos meios para satisfazer suas necessidades, a produção da vida material, [...] condição fundamental de toda história”.

A vida social é prenhe de conflitos e enorme exigência e de infinitas relações e novas necessidades. As transformações que acontecem a cada momento abarcam todas as esferas da vida humana, seja nas forças de produção, na política, na cultura, na ciência, na religião, na tecnologia, nas relações e na própria vida quotidiana, ou na vida vivida. Em todo esse emaranhado da vida social, o próprio homem transforma-se. 
Logo, a necessidade é "[...] o fenômeno ou acontecimento que sobrevém sem falta, sob determinadas condições”, é, portanto, aquela que "[...] emana da essência, da natureza interna do fenômeno em desenvolvimento" (AFANASIEV, 1968, p. 169-170), visto que a necessidade manifesta-se sob determinadas condições objetivas do mundo social e essas condições estão em constantes mudanças. Logo, as necessidades humanas mudam e desenvolvem-se.

No dicionário do pensamento marxista, editado por Tom Bottomore (2013), necessidade vem assim explicitada:

As tendências determinam as necessidades. Pode, porém, haver obstáculo à realização das tendências. Assim, em oposição às tradicionais relações modais da necessidade, não se deduz a realidade, mas, no máximo, a possibilidade. Se, portanto, alguma coisa é necessária, se e quando ocorrer, sua ocorrência está fundamentada numa tendência. Os obstáculos às tendências nem sempre são acidentais; a negatividade dos todos é uma base para tendências conflitantes ou contraditórias dentro desses todos. Devido a esse conflito, a necessidade, assim como a lei científica, leva antes a desenvolvimentos ideais do que a desenvolvimentos concretos. [...]. A tendência à socialização do local de trabalho leva necessariamente à propriedade social dos meios de produção. Essa tendência, porém, é contrabalançada pela tendência a disciplinar a força de trabalho, que leva necessariamente a um controle cada vez menor, pelos trabalhadores, do local de trabalho. Nenhum desses desenvolvimentos ideais - que se revelem através da necessidade - corresponde ao local de trabalho real. (BOTTOMORE, 2013, p.348).

Visto que o conceito de necessidade é complexo, uma determinada definição está acoplada a quem utiliza o termo e ao contexto sociocultural em que é aplicado.

Ainda segundo o dicionário do pensamento marxista, Marx explicita que "O sistema das necessidades humanas" comporta duas dimensões: a fisiológica e a histórica, ambas vinculadas ao consumo, como destaca Bottomore (2013).

[...] As necessidades fisiológicas básicas devem ser distinguidas das necessidades historicamente determinadas, que têm origem nos sucessivos avanços 
no desenvolvimento das forças produtivas e na relação de forças sempre em transformação, entre as classes sociais ("popularização" de bens e de serviços de consumo antes reservados à classe dominante); [...]. (BOTTOMORE, 2013, p.133)

Dessa forma, as potencialidades das necessidades podem ser reveladas, pois, como já afirmamos, elas mudam e desenvolvem-se. Todas as relações universais das necessidades emergem das condições, as quais os homens, seres relacionais, entrelaçam-se na vida social.

Logo, corroboramos com Marx e Engels (2007) que, tal como os indivíduos exteriorizam suas vidas, assim eles são.

Somos seres vivos e conscientes. Assim sendo, seres que se comunicam através da linguagem, seja ela verbal e não verbal ${ }^{1}$. A linguagem nasce tal como a consciência, da carência, da necessidade de intercâmbio entre os homens.

E é a partir dessa necessidade de comunicação, que discutiremos a respeito das necessidades formativas do professor. Comunicação que se estabelece, a partir de tecidos de interações, que estruturam as unidades dialéticas, a qual tem importância crucial no que queremos transmitir.

Considerando que as pesquisas sobre as necessidades formativas de professores são um campo necessário e, segundo Rodrigues e Esteves (1993), que ainda é pouco explorado nos processos de formação inicial e continuada, propusemo-nos a compreender e explorar esse objeto.

Dessa forma, não podemos somente visualizar o processo

[...] para compreender o mundo de forma plena e se comunicar o ser humano usa as duas formas de expressão: verbal e não-verbal, que são muitas vezes, campos complementares e simultâneos. [...] linguagem é considerada como a capacidade humana de articular os significados coletivos e compartilhados em sistemas arbitrários de representações, que variam de acordo com as necessidades e experiências da vida em sociedade. Todo este processo só é possível porque a linguagem é uma herança social, uma "realidade primeira" que, uma vez assimilada, envolve os indivíduos e se faz com que as estruturas mentais, emocionais e perceptivas sejam reguladas pelo seu simbolismo. (OLIVEIRA, 2007, p. 7). 
formativo dos professores, mas, por ora, subverter o que está posto e dentro das possibilidades abstratas, dispor de condições necessárias para efetivação da realidade. Neste sentido, Bandeira (2014, p. 54) explicita que "se as condições não forem criadas para compreensão da necessidade como premissa da possibilidade, não restam dúvidas, as necessidades ficam dissimuladas na sua forma mais comum, ou seja, nas casualidades".

Destarte, então subsidiamo-nos nos diálogos já existentes para afirmar que as necessidades formativas, caracterizadas por D`Hainaut (1979), fundamentam-se em cinco critérios de possibilidades fundamentais, conforme Quadro 1.

\section{Quadro 1. Caracterização das necessidades.}

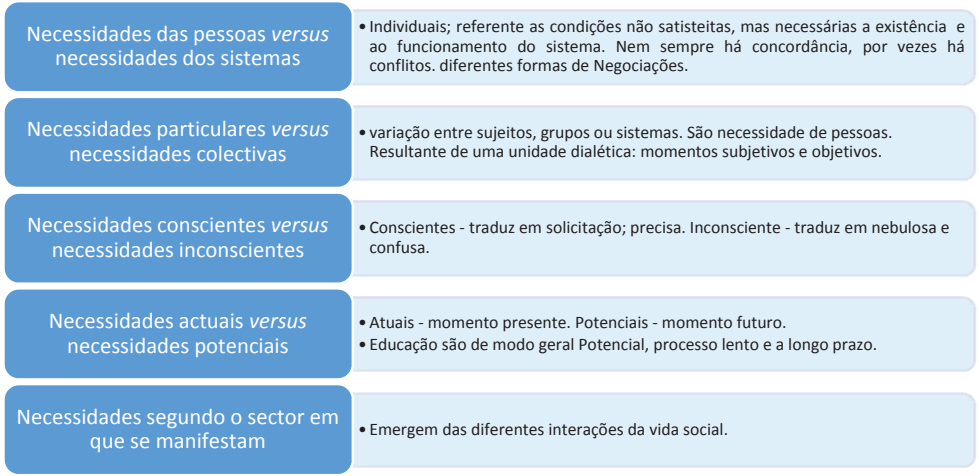

Fonte: Elaboração própria baseada em Rodrigues e Esteves (1993, p. 14 - 15)

Deste ponto de vista, as necessidades formativas dos professores estão indiciadas “[...] como categoria de devir, na qual a colaboração e reflexão revelam-se pertinentes para expandir a compreensão dos professores para além do fazer docentes", afirma Bandeira (2014. p. 54).

\section{Ação do homem: Planejar}

Uma das ações do homem, o ato de planejar é uma atividade tão antiga quanto o homem e, para o pesquisador, o planejar é 
"antecipar" mentalmente uma "ação a ser realizada" e "agir" de acordo com o que foi previsto; é "buscar a fazer algo incrível", "essencialmente humano: o real ser comandado pelo ideal" (VASCONCELOS, 2007, p. 35).

O ato de planejar é importante. Vasconcelos (2007) elenca dois pressupostos devido a essa importância - primeiro: explicita a relação teoria - prática, o planejamento auxilia a concretização daquilo que almejamos; segundo: aponta que o que é possível de acontecer, de certa maneira, permite interferir na realidade.

Assim, pensar no processo de planejar, faz-nos remeter a querer mudar algo, acreditando na possibilidade de mudança da realidade e percebendo a necessidade da mediação teórico - metodológica, vislumbrando, assim, a viabilidade de realizar a ação.

Nesse contexto, Vasconcelos (2007) enfatiza que o pressuposto fundamental do planejamento é a "necessidade de mudança". Essa necessidade está imbricada nos homens, pois, a cada interação, relação, discurso, surgem novas necessidades, as quais, como sujeitos ativos, queremos suprir.

Entretanto, um dos grandes nós que fica evidente no âmbito educacional, no que tange ao planejamento é as possibilidades e as condições reais e objetivas desse ato acontecer. Possibilidades que são, por vezes, reais e abstratas. As abstratas são aquelas que não podem ser realizadas nas condições históricas existentes. Mas, isso não nos permite enfatizar que são possibilidades impossíveis, uma vez que elas podem, num futuro, quem sabe bem próximo, realizarem-se desde que as condições sejam amadurecidas e adequadas para esse fim (AFANASIEV, 1968).

Já a possibilidade real é a que existe em condições históricas reais e concretas, com as premissas necessárias para a sua concretização. No entanto, é importante que, no ato de planejar, os professores compreendam que as diferenças dessas possibilidades são relativas, pois, a qualquer momento, as abstratas podem tornar-se reais, isso não é utópico. Isso é processo de desenvolvimento. Basta olharmos para a verdade. 
Tais possibilidades estão presentes em cada tomada de decisão dos sujeitos e também se manifestam no momento em que a decisão é objetivada. (LESSA, 2014).

Planejar incide em decidir! Incide ação! Exige reconhecer os sujeitos, como sujeitos históricos, sociais e vivos.

O planejamento é uma questão desafiadora, posto que ele só tem sentido, como afirma Vasconcellos, se o sujeito coloca-se numa perspectiva de mudança, estabelecido pela necessidade, que é inerente ao sujeito vivo.

Ao descrever planejamento, Vasconcelos (2007) enfatiza como "methodos da práxis pedagógica", dando ênfase à ressignificação da prática do planejamento.

$\mathrm{Na}$ educação, um fator que merece destaque é que podemos planejar em diferentes níveis de abrangência, como o planejamento do sistema de educação - em nível nacional, estadual e municipal; o planejamento da escola - projeto pedagógico e o planejamento curricular - que se expressa na proposta geral das experiências de aprendizagem que serão oferecidas pela escola e incorporadas nos diversos componentes curriculares.

O planejamento mais próximo da prática do professor e da sala de aula é o plano de aula ou projeto de ensino aprendizagem. Segundo Vasconcelos (2007, p. 95-96), “o planejamento da ação educativa baseada no trabalho por meio de projetos de aprendizagem desenvolvidos na escola geralmente de caráter interdisciplinar o autor o tipifica como projeto de trabalho".

Sendo assim, para que todo esse diálogo materialize-se, é preciso compreender onde e quais são as necessidades dos sujeitos envolvidos nesse ato, pois, a perspectiva de transformação educacional deverá partir de um processo de reagregação dos sujeitos. Ademais, estabelece que a instituição deva propiciar o encontro da comunidade escolar para "a reflexão, a ação sobre a realidade, numa práxis” (VASCONCELOS, 2007, p. 163).

Considerando que, conforme Vasconcelos (2007, p. 162), "[...] o trabalho do professor tem uma dimensão essencialmente 
coletiva: não é o único que atua na escola e o que faz não é para si, já que presta um serviço à comunidade", é necessário encontrarmos formas de possibilitar um entrelaçamento dos sujeitos, professor de Matemática em formação, se assim viabilizarmos, podemos inferir que esse espaço formativo é um espaço revolucionário.

Em virtude, desse "espaço revolucionário", Vasconcellos (2007, p. 162) sublinha que: “[...] são espaços necessários e privilegiados para a reflexão crítica e coletiva sobre a prática da sala de aula, bem como do replanejamento [...]". Consideramos, dessa forma, esse espaço favorável às articulações dos saberes, dos conhecimentos historicamente acumulados, dos confrontos, reconstruções e apropriações de conhecimentos, que não ocorrem espontaneamente, mas por meio dos processos educativos planejados para esse fim.

\section{Caminhos Metodológicos}

No processo metodológico da investigação, atuamos com a pesquisa colaborativa. Balizamos em uma concepção de organização e técnicas que coadunam com os princípios que nortearam a pesquisa, em particular, a investigação colaborativa, por considerá -la a modalidade mais apropriada à consecução dos objetivos que nos propomos a atingir.

Um marco importante que deve ser ressaltado é que “[...] colaborar não significa que todos devam participar das mesmas tarefas e com a mesma intensidade, mas que, sobre a base de um projeto comum, cada partícipe preste sua contribuição específica, isto é, contribua para beneficiar esse projeto" (IBIAPINA, 2008, p. 31). Dessa forma, as trocas de funções acontecerão, de acordo com as necessidades que forem emergindo no decorrer da pesquisa.

O objetivo de trabalhar colaborativamente é oportunizar aos sujeitos participarem como co-produtores da investigação. Enfatizamos que a pesquisa colaborativa efetiva-se no âmbito educacional como atividade de co-produção de saberes, desencadeando formação, reflexão e desenvolvimento profissional, de forma colaborativa, visando à transformação de uma dada realidade. Assim, 
vislumbramos que a formação mediante processos colaborativos possibilita aos profissionais do magistério da educação básica de Matemática discutir, organizar informações e interpretá-las, o que culmina na formação de uma consciência de sua condição de sujeito no seu processo formativo. (IBIAPINA, 2008)

Para o desenvolvimento deste artigo, utilizamos apenas uma dessas unidades - as narrativas diárias e os diálogos - em momento caracterizado como "Significado do Planejamento; "Necessidade e importância do planejamento", os quais indicam as necessidades formativas dos professores em formação, aqui evidenciadas pelos grupos constituídos na aula que preconizaram experiências singulares na trajetória de constituição dos sujeitos vivos e inacabados, sempre em constituição, logo repleta de interferências, de confrontos na perspectiva de transformações, isto é, de atividade puramente humana.

Partimos do princípio que planejar é inerente aos sujeitos vivos e históricos. O ser humano durante toda a sua existência projeta, dialoga, narra casos, histórias, desejos, emoções, decepções, ideações e materializa mediante as possibilidades de suas ideações. Esses são alguns dos infinitos elementos que constituem a existência do sujeito que planeja.

A existência envolve necessariamente a cultura, a linguagem, a comunicação em níveis complexos e profundos, sujeitos com possibilidades de intervir no mundo, de planejar, de comparar, de ajudar, de decidir, de romper, de confrontar e, por fim, transformar os objetos e os sujeitos dessa existência. (FREIRE, 1999).

Logo, ao tratarmos desses sujeitos no viés educacional, não podemos esquivar que, na verdade, o princípio educacional inicia-se com a própria humanidade, com sujeitos vivos e ativos e desenvolve-se e atualiza para cada contexto social, cultural, histórico e político em um determinado tempo e localidade. Nesse viés, todos os sujeitos e objetos, que fazem parte integrante da sociedade, educam. Sendo assim, o sujeito docente, ou futuro docente, é responsável na construção de sua história, de suas necessidades da vida 
profissional e pessoal. No entanto, esse processo de compreender a relação teoria e prática é condição indispensável e fundamental para possibilitar a práxis.

Com esses entendimentos, explicitamos que esse diálogo compartilhado aconteceu em uma das aulas da disciplina de Prática de Ensino de Matemática III na UFMS, encontros com alunos da instituição de ensino, a pesquisadora e a professora de sala.

Assim, deu-se o início à aula, mediante um diálogo entre os sujeitos desse contexto. Esse diálogo deu-se com o objetivo de informar, descrever e confrontar os conceitos sobre o ato de ensinar e as suas necessidades inerentes ao processo por meio do diálogo compartilhado dos eus e outros eus.

Logo, consideramos que o diálogo é uma ferramenta necessária, na medida em que os seres humanos criam, reinventam, cada vez mais, em seres criticamente comunicativos e transformadores. No movimento de sala de aula, na perspectiva de parceria, o diálogo é o momento em que os seres humanos encontram-se para informar, discutir, pensar, repensar e refletir sobre a sua realidade, assim como para construí-la e transformá-la. Cabe ressaltar que o diálogo está imerso nas relações sociais e que elas são permeadas por conflitos, tensões e contradições.

A seguir, apresentamos algumas análises referentes aos diálogos compartilhados no movimento de (re) pensar o ato de planejar via análise das necessidades formativas de professores de Matemática em formação.

\section{Alguns resultados...}

Como já explicitamos, a atividade de planejar é inerente ao ser humano e isso é singular na diferenciação dos outros animais. $\mathrm{O}$ homem tem a capacidade de escolha.

Dessa forma, considerando a singularidade do contexto e o campo específico da licenciatura em Matemática, que foi a disciplina Prática de Ensino de Matemática III, com o estudo sobre o ato de planejar, consideramos as práticas sociais constituídas de saberes, 
tendo em vista esse ato inerente do sujeito, que, por momentos, está condicionado a uma variedade de processos, sejam eles: rotineiro, tradicional, mecânico, baseados muitas vezes por tradições, costumes ou crença, materializados pelo entrelaçar das relações sociais.

Com esses entendimentos, explicitamos que o movimento de análise deste texto é a partir de fragmentos selecionados dos encontros. Materializados mediante o planejamento realizado pelos grupos, com os seguintes conteúdos: "Arranjo simples e aplicação no estudo da matemática discreta, Binômio de Newton; Análise combinatória - Princípio Fundamental da Contagem", escolhidos pelos grupos, mediante melhor conhecimento e habilidades, refletidos na tentativa de descrever a produção no contexto da Educação Brasileira.

Cada grupo fez a análise do planejamento realizado (Quadro 2), mediado por alguns pontos a serem refletidos, que foram entregues a cada equipe. Veja na página seguinte o quadro 2.

Assim, com a dinâmica de semicírculo, os grupos foram dialogando, dentre os pontos elencados. Em se tratando do modelo de planejamento realizado, os grupos evidenciam que, depois de debates e discussões, concluíram quanto ao modelo de planejamento, ao elaborarem a preocupação foi: adaptação de um modelo já pronto (G1); não sabemos (G2); modelo tradicional (G3); modelo? Não conhecemos (G4); Reproduzido por pesquisas da internet (G5), ao trazer essa discussão com os alunos, a intenção era verificar o conhecimento prévio.

O momento era de falar, informar e descrever, sem rotular " certo ou errado. " Era descrever o que o grupo havia discutido ao analisar a própria produção.

No entanto, compreendemos que "[...] os modelos de planejamento de ensino não são lineares e nem puros, uma vez que são superados e não substituídos, [...] (ARAUJO, 2010, p. 59), mas o que foi possível ao grupo maior foi perceber, após esse momento, é que todos necessitavam de momentos de estudos para conhecer os modelos de planejamentos existentes. Conhecer a história sobre como esse conceito vem se desenvolvendo e qual a sua importância na nossa profissão. 


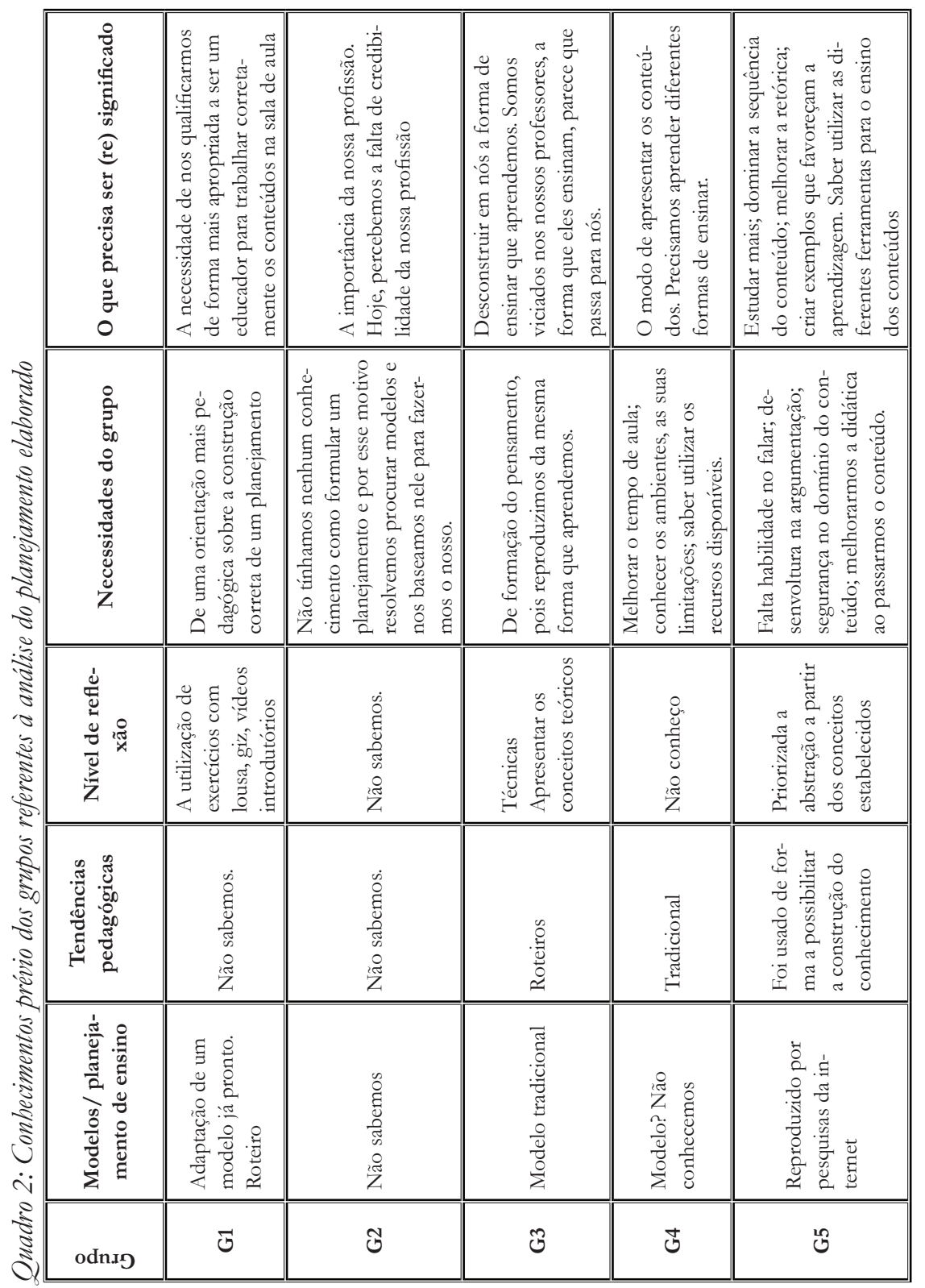

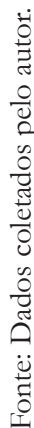


Araujo (2010, p. 89) descreve essa história e ficam evidentes os modelos de planejamento na perspectiva liberal e na visão progressista, como: “[...] princípio prático (roteiro), princípio prático espontâneo, princípio instrumental", na perspectiva liberal de educação, e o "[...] participativo e dialógico-colaborativo" na visão progressista de educação, todos entrelaçados na história educacional brasileira. Foram esses conceitos que, mais tarde, trabalhamos com os grupos e reelaboramos os planejamentos, visto o conhecimento (res) significado.

Nesse tom, Freire (1967, p. 12) elucida que "[...] as palavras são igualmente expressões da prática dos homens, e conscientizar é assumir a consciência do fato". Logo, essa conscientização "abre caminho à expressão das insatisfações sociais é porque estas são componentes reais de uma situação [...]" (FREIRE, 1967, p.11). Dessa forma, iniciou-se a busca por suprir tais necessidades do grupo.

Cabe, aqui, explicitar que, como Pimenta (1998) enfatiza, os cursos de licenciatura precisam tomar outros caminhos, é nítida a necessidade dos alunos, visto as possibilidades, as condições em que eles encontram-se não favoreceram o conhecimento da história, de uma das ferramentas mais importante na profissão professor.

Mas, como seria possível esses conhecimentos em um curso de Matemática? Perguntamos que professor queremos formar? Para que sociedade? Em que tempo? O homem é fruto do meio. Dentre esses grupos, havia em torno de 20 alunos, futuros professores de Matemática. E, apenas um classificou o modelo como "roteiro", em que a reflexão é apenas repetitiva e mecânica, uma tendência veementemente tradicional. Mediante essa constatação, há importância do "informar e descrever", na perspectiva de conhecer os sujeitos, de explicitar as necessidades, para, depois, decidirmos juntos o caminho a seguir.

Destarte, desse movimento "prévio" do grupo sistematizado no Quadro 2, apresentado anteriormente, ficam evidentes as seguintes necessidades formativas, conforme Figura 1. 
Figura 1. Necessidade formativas indicadas.

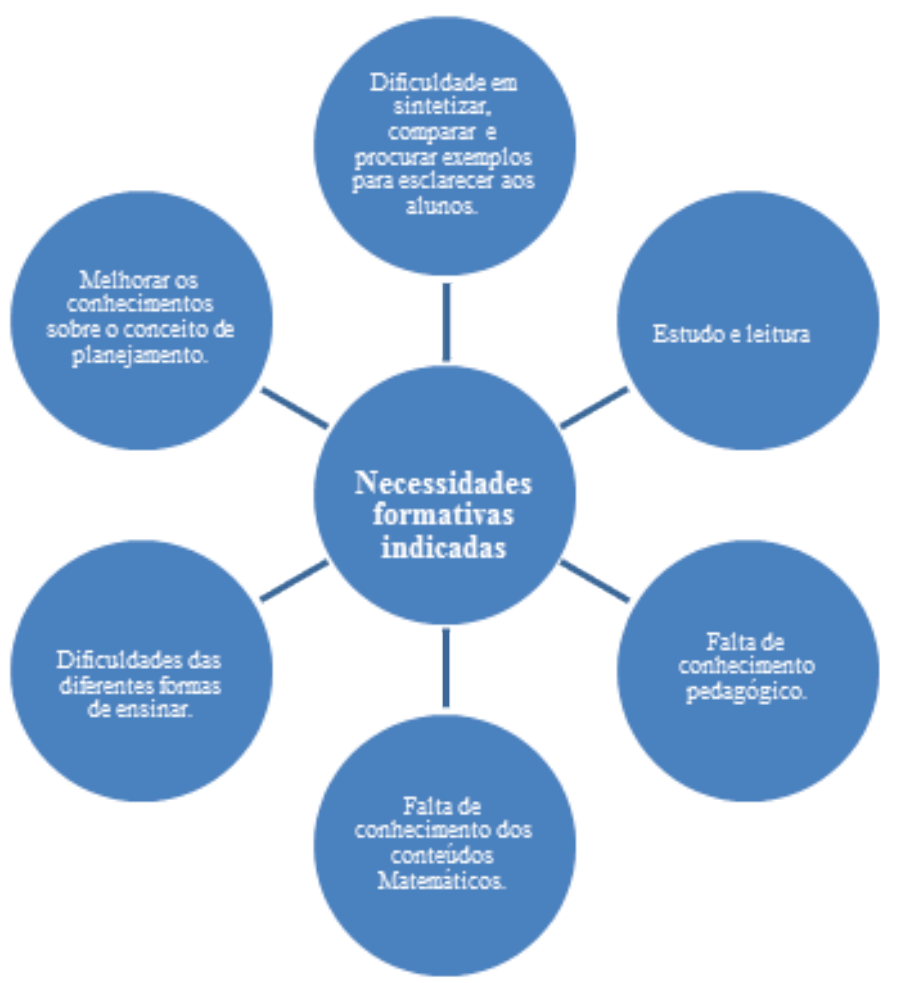

Fonte: Elaboração própria.

Ademais destacamos que as necessidades formativas não surgem do nada e, segundo Bandeira (2014, p.197), nem desaparecem espontaneamente sem deixar rastro, mas são "manifesta de diversas formas, em decorrência, o fim de uma delas é o começo de outra, e quando atendida como possibilidade, gera práxis".

Nessa perspectiva de, primeiramente, indicar as necessidades formativas do sujeito e do grupo, podemos inferir, corroborando com Bandeira (2014, p.56), que a medida que os professores conhecem as suas necessidades, "parece diminuir o grau de incerteza quanto ao que deve ser feito, conduzido, inclusive a um nível de 
satisfação com a situação profissional [...]”. Dessa forma, a medida que os professores indicam as suas necessidades, indicam também o conjunto de fatores que as influenciou.

Esse movimento de interação entre os "eu e outros eu", Ibiapina (2016, p. 49), reforça que os sujeitos "negociam sentidos, compartilham significados, questionam leis fossilizadas, concordam ou discordam dos pontos de vista expostos pelos companheiros, fazendo uso de descrições, informações e confrontos justificados, que desencadeiam a reelaboração das práticas e a compreensão da unidade teoria e prática".

Nesse ínterim, os sujeitos estão entrelaçados com as tarefas indissociáveis: reflexão/conhecimento/interpretação da realidade e transformação. Esse movimento deverá ocorrer da seguinte maneira: a partir da prática, refletir sobre a prática e, por fim, transformar a prática.

O compromisso dos sujeitos nas interações e mediado pelo trabalho que realizam dá o real sentido às ações, ao oficio de ser e agir como profissional do ensino. Lelis (1999) salienta que o eixo essencial para a construção desse profissional tem as seguintes características: sensibilidade, coragem, competência para enfrentar os riscos inevitáveis do desconhecido e a capacidade de lidar com as diferenças e que tudo isso desenvolve-se a partir de nossas práticas, de modo que não existem receitas. Logo, para adquirir o compromisso não existe fórmula ou receitas prontas, de tal forma que somente o fazer - refletir poderá indicar caminhos, o rumo da práxis.

\section{Considerações finais}

Anunciamos algumas ideias nos moldes de considerações finais, decorrentes de alguns indícios de caminhos percorridos nessa caminhada de investigação, pesquisa e formação.

Destarte, o que objetivamos neste artigo era explanar sobre a dinamicidade, a complexidade e a mutabilidade das necessidades formativas dos professores de Matemática em formação, a partir da parceria colaborativa no (re) pensar o ato de planejar. 
Consideramos que a colaboração é atividade de partilha, que pode promover desenvolvimento mútuo para os colaboradores, na medida em que as mediações criam possibilidades para o questionamento crítico, no entanto, sob tal perspectiva, segundo Ibiapina (2016), as ações formativas críticas precisam ser organizadas com intencionalidade e a partir das necessidades formativas dos sujeitos. Dessa forma, as necessidades formativas orientam quais caminhos devemos seguir no processo formativo dos professores de Matemática em formação.

Ponderamos que essa síntese não representa algo pronto e acabado, mas a gênese de novas etapas, novos saberes e descobertas, novas necessidades formativas, novos entrelaçamentos que resultaram em outros novos recomeços, num movimento cíclico e jamais linear.

Precisamos urgentemente formar professores que subvertam o que está posto, professores inquietos, curiosos, que ousem dialogar, viver o processo formativo.

\section{Referências}

AFANASIEV. V. Fundamentos de Filosofia. Trad. Edney Silvestre. Rio de Janeiro: Editora Civilização Brasileira S.A., 1968.

ARAUJO, M. P. O processo dialógico: conceito de planejamento de ensino internalizado pelos professores de ensino superior e a prática pedagógica 2010. 197f. Dissertação (Mestrado em Educação.) - Universidade Federal do Piauí.

BANDEIRA, H. M. M. Necessidades formativas de professores iniciantes na produção da práxis: realidade e possibilidades. 2014. 248 f. Tese (Doutorado em Educação.) — Universidade Federal do Piauí, Teresina.

BOTTOMORE, Tom. Dicionário do Pensamento Marxista, Rio de Janeiro: Zahar, Edição digital: abril 2013.

FREIRE, P. Educação como prática de liberdade. Rio de Janeiro: Paz e Terra, 1967.

FREIRE, P. Pedagogia da Autonomia. Saberes Necessários à Prática Educativa. São Paulo: Paz e Terra, 1999. 
IBIAPINA, I M L. M. Pesquisa Colaborativa: Investigando, Formação e Produção de Conhecimentos. Brasília: Líber Livro Editora, 2008. 136 p.

IBIAPINA, 1. M. M. Reflexões sobre a produção do campo teórico metodológico das pesquisas colaborativas: gênese e expansão. In: Ivana Maria. Lopes de Melo Ibiapina, Hilda Maria Martins Bandeira, Francisco Antonio. Machado Araujo (orgs.) Pesquisa colaborativa: multirreferenciais e práticas convergentes, 2016, p.33-62.

KONSTANTINOV. F. V. fundamentos da filosofia marxista lenista. Trad. João Alves Falcato. Novo curso editores. Venda Nova - Amadora. Portugal, 1975.

LELIS, I. A. A relação teoria-prática na formação do educador. In: CANDAU, V. M. F. (org) Rumo a uma nova didática, 9 ed., Petrópolis, 1999, p. 86 -89.

LESSA, S. O estudo e o revolucionário. Por que não estudamos? São Paulo: Instituto Lukács, 2014.

MANACORDA, M. A. História da Educação: da Antiguidade aos nossos dias. 13. ed. São Paulo: Cortez, 2010.

MARX, K; ENGELS, F. A Ideologia Alemã. 1ª ed. São Paulo: Boitempo, 2007.

PIMENTA, S. G. Formação de professores: saberes da docência e identidade do professor. In: FAZENDA, I. (Org.). Didática e interdisciplinaridade. Campinas-SP: Editora Papirus, 1998. p. 161-178.

PONTE, J. P., JANUÁRIO, C., FERREIRA, I. C., \& CRUZ, I. (2000). Por uma formação inicial de professores de qualidade. (Documento de um grupo de trabalho do CRUP - Conselho de Reitores das Universidades Portuguesas) http://www.educ.fc.ul.pt/docentes/jponte/artigos-por-temas.htm. Acesso em 16 de março de 2018.

RODRIGUES, A.; ESTEVES, M. A análise de necessidades de formação de professores. Coleção Ciências da Educação. Porto: Porto Editora, 1993.

VASCONCELOS, C. S. Planejamento: projeto de ensino-aprendizagem e projeto político-pedagógico. 17. ed. São Paulo: Libertad, 2007. 
Kely Fabrícia Pereira Nogueira

Doutoranda em Educação Matemática

Universidade Federal de Mato Grosso do Sul - UFMS

Bolsista FUNDECT

Email: kelyn230@gmail.com

\section{Patrícia Sandalo Pereira}

Doutora em Educação Matemática

Diretora do Instituto de Matemática e Docente no Programa de Pós-Graduação em Educação Matemática e no Doutorado em Ensino de Ciências

Universidade Federal de Mato Grosso do Sul - UFMS

Email: sandalo.patricia13@gmail.com 